\title{
Der Vater des Archimedes.
}

\section{Von Prof. Dr. F. Blass in Kiel.}

Auf die Frage, wer der Vater des Archimedes gewesen, giebt uns unsre, über die Lebensumstände der berühmten Mathematiker des Alterthums sehr karge Ueberlieferung keine Antwort. Ich glaube aber, dass bei Archimedes selbst sich eine Stelle findet, welche, richtig verbessert, den erwünschten Aufschluss giebt. Dieselbe steht

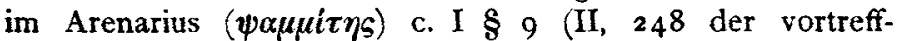
lichen neuen Ausgabe von Heiberg), und lautet nach der Ueberlieferung:

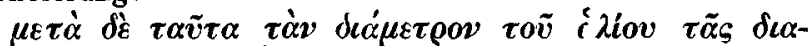

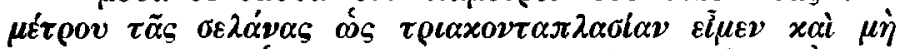

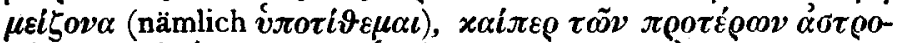

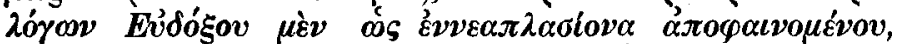

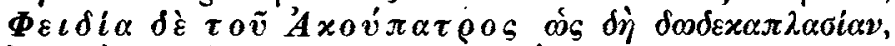

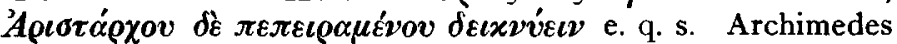
nimmt für seine Berechnung die Grösse des Sonnendurchmessers $=30$ Monddurchmessern an und hebt hervor, dass er mit dieser Aunahme über alle früheren Astronomen hinausgehe; denn Eudoxos habe ihn $=9$ Monddurchmessern berechnet, Pheidias $=\mathrm{I} 2$, Aristarchos $=$ zwischen 18 und 20.

Nun kennen wir den Eudoxos, Plato's Zeitgenossen, und den Aristarch von Samos, den ersten Aufsteller des Copernikanischen Weltsystems; wer ist aber Pheidias? Niemand weiss es, und was Archimedes zur Kennzeichnung

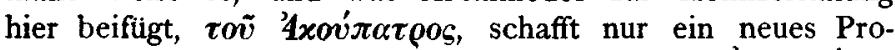
blem. Man nimmt das als Vatersnamen; aber 'Axovл $\dot{\alpha} \tau \eta \varrho$ ist nach den Gesetzen der griechischen Wortbildung ein

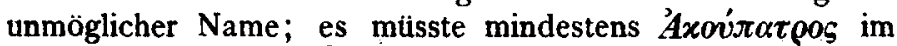

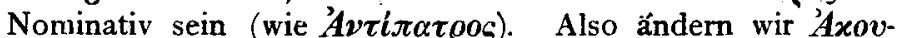

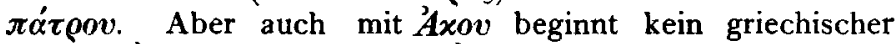

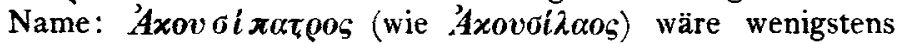
möglich, aber doch unter den Tausenden von überlieferten griechischen Namen keineswegs wirklich vorkommend. Somit hat denn Professor Madvig in Kopenhagen, wie aus Heiberg's Ausgabe ersichtlich, vielmehr die Bezeichnung des Vaterlandes in dem Axovisatoos gesucht. So heisst

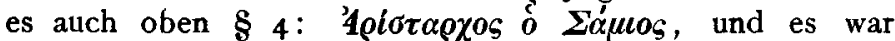
natürlicher, dass Archimedes den wenig bekannten Pheidias nach seinem Vaterlande kennzeichnete als nach seinem
Vater. Aber wie wollen wir, ohne gewaltsamste Aenderung

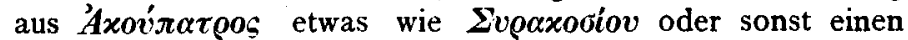
Gentilnamen machen? Ist also auch dieser Weg ziemlich versperrt, so thun wir wohl uns zu erinnern, dass das Wort erst durch die Herausgeber zum Eigennamen gemacht ist, weil sie es nicht verstanden; in den Handschriften ist alles klein, d. h. mit einerlei Art von Buchstaben geschrieben. Auch die Trennung der Wörter, die Setzung von Accenten u. dergl ist in den Handschriften wenigstens jüngeren Ursprungs, und hat keinerlei Autorität. So werden wir das $\pi \alpha \tau \varrho o ́ S$ zunächst absondern dürfen, als Genitiv von $\pi \alpha \tau \dot{\eta} \varrho$; axov aber, was so nichts ist, wird mit einer minimalen

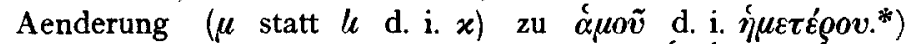
Weil die Abschreiber die Dorische Form ¿́ $\mu o_{\zeta}$ für $\eta \mu \varepsilon \varepsilon \varepsilon-$ oos nicht verstanden, war es ihnen um so leichter, die ähnlichen Buchstaben zu verwechseln. Also $\Phi_{\varepsilon \iota d i \alpha}$ (Dori-

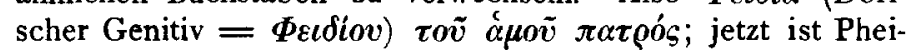
dias genügend gekennzeichnet, und es begreift sich sofort, weshalb der Sohn Archimedes ihn wohl erwähnt, sonst aber Niemand. Auch die Chronologie stimmi zu seiner Nennung zwischen Eudoxos und Aristarch; denn wenn letzterer auch erheblich älter als der um 287 geborene Archimedes war, so war er doch nicht älter als der Vater desselben. Ferner entspricht es sonstigen Erscheinungen im Alterthum, dass Archimedes den Beruf oder das Studium seines Vaters aufnahm; denn wie die Plastik und die Arzneikunde, so wurden auch andere Wissenschaften und Künste erblich in einzelnen Familien gepflegt. Dass aber sunser « statt , meins steht, darf nicht auffallen; denn wie andre Schriftsteller redet auch Archimedes häufig von sich

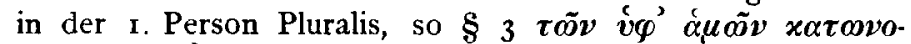
$\mu \alpha \sigma \mu t v \omega v \dot{\alpha} \varrho \iota \vartheta \mu \tilde{o} \nu$, obwohl der Satz, worin dies steht, mit '̧́ó beginnt.

Wenn also alles stimmt und nichts widerspricht, so dürfen wir die Verbesserung der Stelle als genügend gesichert betrachten und den Archimedes als Sohn des Astronomen Pheidias bezeichnen, welcher $u$. a. eine Berechnung über das Grössenverhältniss von Sonne und Mond angestellt hatte.

Kiel 1882 Dec. 20.

*) So ist auch unten $\$ 14$ das handschriftliche है! $x_{0}$ in है! $\mu \dot{\varepsilon} v$ verbessert worden.

\section{Angelegenheiten der Centralstelle für astronomische Telegramme.} hinzugekommen.

$\mathrm{Zu}$ den in Nr. 2472, 2476 und 2480 aufgeführten Theilnehmern sind die Sternwarten zu Coimbra und Odessa Kiel 1883 Jan. 15.

A. Krueger.

\section{Inhalt:}

Zu Nr. 2487-88. H. Seeliger. Ueber die Vollständigkeit wiederholt ausgeführter astronomischer Durchmusterungsarbeiten. 225. - $T$. $N$. Thiele Neue Methode zur Berechnung von Doppelsternbahnen. 245. - P. G. Stanislao Ferrari $S$. $\mathcal{F}$. Ingresso di Venere sul disco solare osservato in Roma il 6 Dicembre 1882. 253. - F. Blass. Der Vater des Archimedes. 255. - $A$. Krueger. Angelegeuheiten der Centralstelle für astronomische Telegramme. 255. 